\title{
Jean-Charles Falardeau (1914-1989)
}

Sociologue, Faculté des sciences sociales

Université Laval

(1941)

\section{“D’une culture canadienne- française. On ne «dirige» pas une culture.”}

Un document produit en version numérique par Jean-Marie Tremblay, bénévole, professeur de sociologie au Cégep de Chicoutimi

Courriel: jean-marie tremblay@uqac.ca

Site web pédagogique : http://www.uqac.ca/jmt-sociologue/

Dans le cadre de la collection: "Les classiques des sciences sociales" Site web: http://www.uqac.ca/Classiques_des_sciences_sociales/

Une collection développée en collaboration avec la Bibliothèque Paul-Émile-Boulet de l'Université du Québec à Chicoutimi Site web: http://bibliotheque.uqac.ca/ 
Cette édition électronique a été réalisée par Jean-Marie Tremblay, bénévole, professeur de sociologie au Cégep de Chicoutimi à partir de :

Jean-Charles Falardeau,

Professeur titulaire, École des sciences sociales de l'Université Laval.

“D’une culture canadienne-française. On ne «dirige» pas une culture.”

Un article publié dans la revue L’Action Nationale, vol. 17, no 3, mars 1941, pp. 209-217.

Avec l'autorisation formelle de la direction de la revue L'ACTION NATIONALE, accordée par M. Sylvain Deschesne, le 5 août 2005.

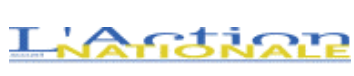

Un gros merci à la revue

$\underline{\text { L’Action Nationale }}$

Courriel : revue@action-nationale.qc.ca

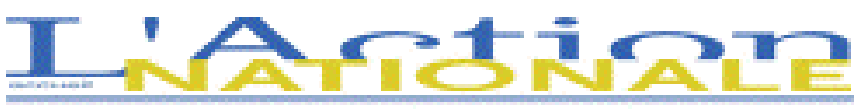

Polices de caractères utilisée :

Pour le texte: Times, 12 points.

Pour les citations : Times 10 points.

Pour les notes de bas de page : Times, 10 points.

Édition électronique réalisée avec le traitement de textes Microsoft Word 2004 pour Macintosh.

Mise en page sur papier format : LETTRE (US letter), 8.5'’ x 11’’)

Édition complétée le 28 août 2005 à Chicoutimi, Ville de Saguenay, province de Québec, Canada.

\section{\& Fait avec}




\section{Table des matières}

I. "Existe-il une culture canadienne-française, définitive ou en voie de formation?”

II. Dans quel sens devons-nous orienter cette culture ? 
Jean-Charles Falardeau (1914-1989)

(1941)

"D'une culture canadienne-française. On ne «dirige» pas une culture.”

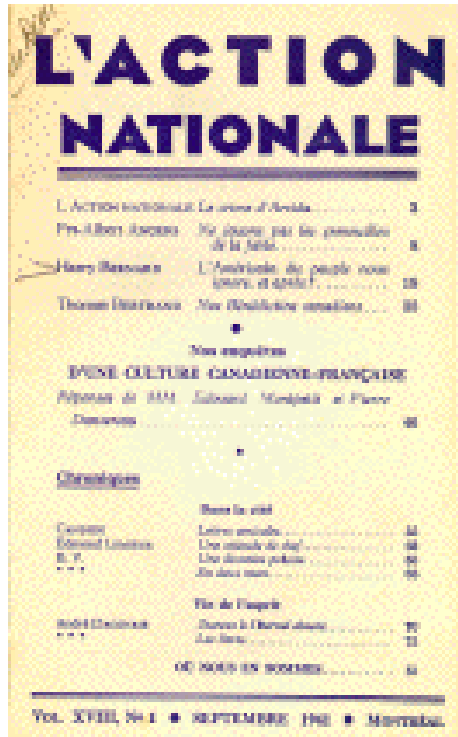

Un article publié dans la revue L’Action Nationale, vol. 17, no 3, mars 1941, pp. 209-217. 


\section{I. \\ "Existe-il une culture canadienne-française, définitive ou en voie de formation ?”}

\section{$\underline{\text { Retour à la table des matières }}$}

Une telle question signifie une incertitude, une susceptibilité, une angoisse. Une approche concrète de sa réponse exigerait, pour que nous ayons quelque chance de nous entendre sur le sens que nous lui donnons et sur la portée de nos conclusions, qu'on précise en premier lieu, en procédant du général au particulier, l'analyse du concept de culture ou de civilisation et qu'ensuite on élucide quelles sont ou quelles seraient les dominantes caractéristiques d'une culture américaine, et plus exactement, d'une culture canadienne.

On dit indifféremment en français : une culture, une civilisation ${ }^{1}$, référant par là soit à un certain style de vie humaine confirmé par une longue habitude collective, soit au processus lui-même de développement rationnel - spirituel, intellectuel et moral - d'un groupement humain. Ramuz dans une étude récente nous suggère une définition doublement opportune qui nous aidera à étayer les prémisses de notre examen de conscience : «Toute civilisation ... est une lente élaboration de valeurs dont l'expression collective n'est que le résultat de nombreuses réussites individuelles, (lesquelles) aussi supposent beaucoup de temps, des loisirs, des réserves, une accumulation laborieuse d'expériences en tout genre. ${ }^{2}$ - Culture : oeuvre de maturation originale, maturation multiforme, stimulée et exprimée d'abord par des voix personnelles, puissantes, significatives. Existe-t-il, en ce sens, une culture simplement canadienne ? Il faudrait ici décrire les modalités de

Maritain, Religion et Culture, pp. 13, 109.

Pages d'un neutre, N.R.F. 1er mars 1940, p. 300. 
ce qu'on appelle la civilisation américaine - style de vie utilitaire, conquérant, tendu vers le futur, le succès matériel, le transitoire, l'immédiat, d'esprit formé aux cultures européennes mais farouchement affranchi - dont la vie canadienne, comme telle, subit une influence incoercible mais a laquelle en même temps elle s'oppose historiquement et culturellement par des contrastes distinctifs. Il suffit d'indiquer ce qui en est une formalité essentielle, et l'on ne peut, je crois bien, exprimer celle-ci avec plus de justesse qu'en répétant les termes mêmes d'une analyse méconnue et d'une rare perspicacité, publiée il y a quelques années par M. E.C. Hughes Ph.D., de l'université McGill : « Canada as a whole is somewhat culturally self-conscious... C'est un fait qu'il existe en notre pays, avec une exceptionnelle intensité, une culture consciousness, faite à la fois d'une opposition intestine entre les conceptions que se font de la culture en général et de leur culture les deux nationalités constituantes du pays, et à la fois d'un tiraillement entre l'influence des États-Unis adjacents et celle de l'Europe (Angleterre, France) ». ${ }^{3} \mathrm{Ce}$ qui caractériserait le Canada sur le plan culturel est en même temps unifié par cet effort de défensive ou de sympathie vis-à-vis des influences américaines et européennes, et dissocié par une faille intime entre les deux éléments ethniques qui en sont les protagonistes.

Avec quelle originalité, dans ce complexe, se dessinerait une culture canadienne-française ? Sans consentir à des rétrospectives historiques pourtant fondamentales considérons les notes typiques qui définissent, soit notre personnalité, soit nos œuvres, par opposition à nos compatriotes anglais - ce qui fait de nous something different - et c'est à l'aide de ces jalons confus qu'il faudra tâcher de discerner plus profondément les possibilités de notre individualité culturelle.

Il y a d'abord la religion catholique qui accentue non seulement la vie individuelle de la plupart des Canadiens français mais jusqu'à notre conscience collective passée et actuelle. Notre vie sociale et politique même, par son organisation paroissiale, ses mœurs patriarcales et ses hiérarchies civiles déférentes et obéissantes vis-à-vis le pouvoir officiel de l'Église, s'en trouve imprégnée, colorée, et se manifeste en définitive en une sorte de traditionalisme d'esprit théocratique. Mais la religion, comme telle, ne peut être identifiée formellement comme un, élément de culture : elle transcende et peut informer, théoriquement, toutes les cultures : ainsi pourrait-elle contribuer a vivifier celle que nous voulons ou que nous devrions avoir, à la condition toutefois que nous en prenions, une bonne fois, une conscience intelligente et non timorée. Le second élément primordial qui nous différencie est notre langue, perpétuée malgré le temps et le milieu, lentement émoussée chez les ruraux et les masses citadines, conservée pure et souple parmi

3 “The French-English margin in Canada”. The American Journal of Sociology. juillet 1933. vol XXXIX, no 1. 
les classes ( ?) ou les individus instruits et cultives, mais qui reste le seul trait d'union avec une France rétrospective (celle du XVIIe siècle). Les événements historiques, par ailleurs, (conquête, oppression, solitude, misère involontaire et ensuite incurablement consciente) ont fait à notre groupe ethnique et ont inspiré a ses premières activités intellectuelles, cette lucidité d'un complexe de vassalité et de jeunesse à retardement : xénophobie latente, colonialisme, une sorte d'avarice, de mesquinerie intellectuelle, une tendance à un insularisme parfois intransigeant, toutes ces dispositions alliées à un impétueux désir de vivre, un courage jamais lasse de reprendre le temps perdu et de faire consacrer un droit de cité injustement méconnu. Nous étions nés, comme groupe américain, de marcottages, de boutures : en outre d'être privés de tuteurs il nous a fallu lutter contre celui qui s'est imposé.

Comment maintenant trouver là les éléments d'une culture canadiennefrançaise ? Nos premières oeuvres littéraires, par nécessité, et nous continuons de vivre de cette prédisposition aujourd'hui héréditaire, sont nées d'un dessein polémique, défensif. ce sont des œuvres, le très grand nombre de nos essais sont encore, des actes de lutte, des tentatives d'affranchissement soit des dangers d'assimilation anglaise, soit de ce que les Canadiens français considéraient comme les périls spirituels d'une osmose intellectuelle avec la France d'après la Révolution. Oeuvres apologétiques, esprit colonial, esprit hermétique, introverti. Nos œuvres de pensée et celles qui sont données comme telles sont, elles aussi, encore à la remorque des systèmes et des penseurs européens : l'enseignement universitaire commence à peine de pouvoir favoriser un milieu canadien-français propre aux essors dynamiques. La poésie, le roman ont été honorés par très, très peu d'œuvres gratuites qui ne fussent pas des copies livresques, des transpositions régionales d'esthétiques françaises ou des brouillons de pamphlets oratoires. Il y aurait, comme substratum fécond, originel et original, à une littérature et à des manifestations de culture canadienne-française, le folklore indien préhistorique ou typiquement canadien ; cet élément substantiel reste potentiel et n'a pas été suffisamment connu, exploité ni élaboré de manière à créer un "climat » spécifiquement canadien-français ni a inspirer nos oeuvres artistiques. Seules la musique et la peinture y rejoignent petit à petit, de même qu'a l'expression de nos décors naturels. Enfin, nos arts techniques ou domestiques pourraient - et ils recommencent de le faire discrètement, admirablement - retrouver la tradition coloniale de nos XVIIe et XVIIIe siècles, la tradition des artisans, orfèvres, potiers, architectes et maçons français, qui nous ont laissé des œuvres qui nous appartiennent. ${ }^{4}$

4 Les révélations imposantes et inépuisables que nous en a faites toute l'œuvre de M. Marius Barbeau. 
Est-ce à dire que, d'ores et déjà, nous pouvons nous réclamer d'une culture qui est nôtre ? je ne crois pas. Il y a, et a des titres divers, dans l'un ou l'autre des éléments que je viens d'esquisser, des possibilités, des incohations, une matière première si l'on veut, d'une culture personnelle. Mais notre vie intellectuelle, malgré nos particularismes accidentels, est malheureusement encore trop imbibée sinon compromise par la promiscuité étatsunienne, trop latente, trop amorphe ou autointoxiquée, trop soudée aux disciplines et aux imitations étrangères, pour que nous ayons raison de nous installer sur un socle définitif et consacré. En outre, et je reviens ici à la définition de Ramuz citée au début, toute culture, toute civilisation se manifeste, des qu'elle est devenue vivante et réelle, par des « réussites individuelles ", Or nous n'en connaissons pas encore chez nous ou si peu ... C'est aux fruits qu'on reconnaît l'arbre : nous n'avons jusqu'ici récolté que des raisins verts, des fagots ou des fruits postiches, bibelots artificiels importés, jolis comme décorations aux grandes fêtes, mais qu'on abandonne au rebut dès que la « visite » est repartie...

\section{II. \\ Dans quel sens devons-nous orienter cette culture?}

$\underline{\text { Retour à la table des matières }}$

Cette deuxième question pose un faux problème ou pose faussement un problème urgent. je refuse et je nie qu'on puisse parler de culture dirigée comme on parle d'économie dirigée. La culture, ou la civilisation, telle qu'on vient d'en parler, la culture humaine, se dit par analogie de l'acte matériel de cultiver la terre. Or, -pas plus qu'on ne peut hâter ou accélérer sans préjudice une culture naturelle, on ne peut diriger, orienter délibérément une Culture a tel ou tel rythme, en tel ou tel sens déterminé. Tout au plus, et cette œuvre reste éminemment féconde sinon nécessaire, peut-on essayer de modifier le climat ambiant dans lequel doit un jour s'épanouir une culture, rénover et stimuler la glèbe humaine d'où elle jaillira, favoriser la lumière, la chaleur, le soleil, préparer des tuteurs, des engrais, des arrosoirs... Oeuvre de discernement et de discrétion, de patience persévérante. De patience surtout, car il faudra attendre que le milieu soit déjà tel qu'il aide a produire de nombreuses Oeuvres individuelles originales, sur plusieurs plans simultanés, et que, réciproquement, ces « réussites individuelles » fassent prendre conscience au milieu de son âme et de son esprit. De telles réussites ne peuvent jamais 
être provoquées rapidement ni artificiellement. Elles sont expression d'une vie, d'un développement organique, et comme telles, participent à la genèse obscure des mystères de la vie.- En quel sens ainsi peut-on aider le milieu canadienfrançais a devenir ce qu'il est et ce qu'il doit être pour, un jour, voir fructifier une culture personnelle ? Est-il légitime ou opportun seulement de se préoccuper à transformer ou à créer un climat culturel canadien-français ? Je réponds oui a cette dernière question, a condition que l'on entende par la un effort intelligent et d'ordre uniquement intellectuel en vue de développer ce qui, en nous, est héréditairement original et différent des autres Canadiens : une affirmation totale de ce que nous sommes, laquelle d'ailleurs doit rester parfaitement conciliable avec une déférence pour la personnalité de nos compatriotes et la co-existence de leur culture. Pour cela, nous devrons, sous peine de nous enliser ou de nous momifier, reprendre un contact total avec la source historique et culturelle de notre vie : la culture française. Nous serons nous-mêmes en intensifiant l'osmose avec le génie français, non seulement avec le génie français du XVIIe siècle ou le Paris de Saint-Sulpice, mais le génie français de tous les âges dans toutes ses manifestations. Ringuet jadis concluait en ce sens une analyse des tendances et des possibilités de la littérature canadienne-française : «Nous nous estimerions heureux si, mettant en commun avec nos frères de France ce que nous pouvons avoir de personnel, nous parvenions a faire reconnaître, sans autre plébiscite, la littérature canadienne-française comme une province intellectuelle de la littérature française. » ${ }^{5}$ Et c'est juste. Cette revification de nous-mêmes devra être l'œuvre d'un enseignement lui-même rénové et pertinent, conscient des multiples réalités où nous sommes immergés : périls de l'américanisme, nécessaire cohabitation avec les Canadiens anglais, postulats et exigences d'une ascendance française et spirituelle.

Tout ceci récapitule peut-être des truismes et des vérités de La Palisse. On est porté à en oublier ou en mésestimer trop souvent quelques-unes.

Jean-Charles FALARDEAU

Fin du texte

5 Les Nouvelles Littéraires, 31 décembre 1938. 